\title{
Mutagenic Effect of Three Ion Beams on Rice and Identification of Heritable Mutations by Whole Genome Sequencing
}

\author{
Yunchao Zheng ${ }^{1,2}$, Shan $\mathrm{Li}^{1,3}$, Jianzhong Huang ${ }^{2}{ }^{-}$, Haowei Fu ${ }^{4}$, Libin Zhou ${ }^{5}$, \\ Yoshiya Furusawa ${ }^{6}(\mathbb{D})$ and Qingyao Shu ${ }^{1,3, *(\mathbb{D})}$ \\ 1 National Key Laboratory of Rice Biology, Institute of Crop Sciences, Zhejiang University, \\ Hangzhou 310058, China; yunchao.zheng@zju.edu.cn (Y.Z.); lishan@zju.edu.cn (S.L.) \\ 2 Institute of Nuclear-Agricultural Sciences, Zhejiang University, Hangzhou 310058, China; \\ jzhuang@zju.edu.cn \\ 3 Zhejiang Provincial Key Laboratory of Crop Germplasm, Zhejiang University, Hangzhou 310058, China \\ 4 Jiaxing Academy of Agricultural Science, Jiaxing, Zhejiang 314016, China; fhw670225@sina.com \\ 5 Biophysics Group, Biomedical Research Center, Institute of Modern Physics, Chinese Academy of Science, \\ Lanzhou 730000, China; libinzhoulz@gmail.com \\ 6 Department of Basic Medical Sciences for Radiation Damages, National Institute of Radiological Sciences, \\ National Institutes for Quantum and Radiological Science and Technology, Chiba 263-8555, Japan; \\ furusawa448@mac.com \\ * Correspondence: qyshu@zju.edu.cn
}

Received: 24 March 2020; Accepted: 23 April 2020; Published: 26 April 2020

\begin{abstract}
High-energy ion beams are known to be an effective and unique type of physical mutagen in plants. However, no study on the mutagenic effect of argon (Ar) ion beam radiation on rice has been reported. Genome-wide studies on induced mutations are important to comprehend their characteristics for establishing knowledge-based protocols for mutation induction and breeding, which are still very limited in rice. The present study aimed to investigate the mutagenic effect of three ion beams, i.e., Ar, carbon (C) and neon ( $\mathrm{Ne}$ ) on rice and identify and characterize heritable induced mutations by the whole genome sequencing of six $\mathrm{M}_{4}$ plants. Dose-dependent damage effects were observed on $\mathrm{M}_{1}$ plants, which were developed from ion beam irradiated dry seeds of two indica (LH15, T23) and two japonica (DS551, DS48) rice lines. High frequencies of chlorophyll-deficient seedlings and male-sterile plants were observed in all $\mathrm{M}_{2}$ populations (up to $\sim 30 \%$ on $\mathrm{M}_{1}$ plant basis); plants from the seeds of different panicles of a common $\mathrm{M}_{1}$ plant appeared to have different mutations; the whole genome-sequencing demonstrated that there were 236-453 mutations in each of the six $\mathrm{M}_{4}$ plants, including single base substitutions (SBSs) and small insertion/deletions (InDels), with the number of SBSs 4-8 times greater than that of InDels; SBS and InDel mutations were distributed across different genomic regions of all 12 chromosomes, however, only a small number of mutations (0-6) were present in exonic regions that might have an impact on gene function. In summary, the present study demonstrates that $\mathrm{Ar}, \mathrm{C}$ and $\mathrm{Ne}$ ion beam radiation are all effective for mutation induction in rice and has revealed at the genome level the characteristics of the mutations induced by the three ion beams. The findings are of importance to the efficient use of ion beam radiation for the generation and utilization of mutants in rice.
\end{abstract}

Keywords: rice (Oryza sativa L.); mutagenesis; mutation breeding; ion beams; whole genome sequencing; mutation spectrum 


\section{Introduction}

Heavy ion beams are a new type of physical mutagen that is different from the traditionally used $\gamma$ radiation in many aspects [1]. They are featured with high LETs (linear energy transfer) and have been demonstrated to induce mutations at a higher frequency, with a wider spectrum and more efficiency [2]. In rice, Yamaguchi et al. [3] first performed a comparative study on the mutagenic effects of helium (He) and carbon (C) ion beams (with LETs of $76 \mathrm{keV} / \mu \mathrm{m}$ and $220 \mathrm{keV} / \mu \mathrm{m}$, respectively) with $\gamma$ rays. They demonstrated that the efficiency of ion beams either equaled or exceeded that of $\gamma$ rays and that the mutation rate of ion beams was higher than that of $\gamma$ rays. $C$ ion beams have since been used in rice breeding programs and several valuable mutant lines have been developed, such as low cadmium rice [4], ultraviolet-B (UVB)-tolerant mutant [5] and extremely late heading mutants [6].

To comprehend the characteristics and frequencies of the mutations induced by mutagens, next generation sequencing (NGS) technologies have been deployed for sequencing the genomes of plants derived from mutagenic treatment. For the chemical mutagen ethyl methyl sulfone (EMS), a genome-wide analysis of induced mutations has been performed in rice [7] and a number of other plant species, e.g., wheat [8-10], foxtail millet [11], Chenopodium quinoa Willd. [12], sorghum [13], tomato [14], Cucurbita pepo [15], peach [16], Lotus japonicus [17] and Jatropha curcas [18]. Similar studies have also been performed for physical mutagens, such as $\gamma$ ray mutagenesis in rice $[19,20]$ and poplar [21], fast neutron mutagenesis in Arabidopsis thaliana [22] and rice [23], and ion beams in Arabidopsis thaliana [24-28]. In Arabidopsis, a comparative analysis showed that $C$ ion radiation could induce more single base substitutions (SBSs) and short insertion/deletions (InDels) than argon (Ar) ion radiation, while the latter generated chromosomal rearrangements and/or large deletions more frequently than the former [28].

Recently, the mutations induced by ion beams have also been investigated in rice by whole genome or exome sequencing. Using an exome-sequencing procedure, Ichida et al. [29] analyzed the characteristics and distribution of the mutations induced by $C$ ion beams in the absence of bias introduced by the visual mutant selections. They observed that the number of mutations within the target exon regions was $9.06 \pm 0.37$ (average $\pm \mathrm{SE}$ ) in unselected $\mathrm{M}_{2}$ lines, which were derived from dry seeds treated with $150 \mathrm{~Gy} \mathrm{C}$ ion beam $\left({ }^{12} \mathrm{C}^{6+}, 135 \mathrm{MeV} / \mathrm{u}, \mathrm{LET}: 23-30 \mathrm{keV} / \mu \mathrm{m}\right)$, and the mutation frequency increased with the increase of the irradiation dose. Two groups further independently performed comparative analyses of the mutations induced by $C$ ion beams and $\gamma$ rays by whole genome sequencing [30,31]. Unlike Ichida et al. [29], both studies analyzed the advanced mutant lines $\left(\mathrm{M}_{4}-\mathrm{M}_{6}\right)$ of a japonica [30] and indica rice [31], respectively. The conclusions of the two studies were quite consistent: both mutagens induced SBSs and small InDels, and $\gamma$ rays induced more variations (particularly SBSs), but less structural variations (SVs) on average than the C ion beams. However, Li et al. [30] observed no significant differences of the proportion of InDels $(\sim 30 \%)$ in plants developed from two mutagens, while Yang et al. [31] reported a higher proportion of InDels in C ion beam induced plants $(25.44 \%)$ than in those from the $\gamma$ rays treatment $(17.85 \%)$. Besides, SVs were only identified in one study [30].

In addition to the commonly used $C$ ion beams, there are other types of ion beams, i.e., nitrogen $(\mathrm{N}), \mathrm{Ar}, \mathrm{He}$, neon $(\mathrm{Ne})$ and iron $(\mathrm{Fe})$ ion beams, that can be used for plant mutagenesis [1]. However, thus far in rice, only $\mathrm{C}$ and He ion beams have been used for mutation induction, though other types of low energy ion beams (known as ion implantation, e.g., $\mathrm{N}$ ) have already widely been used [32]. In the present study, the mutagenic effect of three ion beams, i.e., argon $\left({ }^{40} \mathrm{Ar}^{18+}\right)$, carbon $\left({ }^{12} \mathrm{C}^{6+}\right)$ and neon $\left({ }^{20} \mathrm{Ne}^{10+}\right)$ were investigated using two indica and two japonica rice lines, and the genome-wide mutations were identified by whole genome sequencing of six advanced mutant lines and the characteristics were further analyzed using bioinformatic tools, with the aim to understand more about the characteristics and usefulness of ion beam mutagenesis in rice. 


\section{Results}

\subsection{Effect of Ion Beam Radiation on $M_{1}$ Plants}

All three ion beams showed damage effects on $\mathrm{M}_{1}$ plants in a dose-dependent mode, with $\mathrm{Ar}$ being more effective than $\mathrm{C}$ and Ne ion beams. Radiation severely affected seedling growth and obviously reduced their survival rate at a higher dose of treatment (Figure 1), with significant effects of radiation type and dose as well as genotype. Among the three ion beams, Ar ion beams seemed much more damaging than the other two. The relative seedling survival rate (RSR) was reduced to $\sim 20 \%$ (LH15, T23 and GS48) to almost zero (DS551) when irradiated with 150 Gy of Ar ion beams, while similar RSR reduction levels were observed for $300 \mathrm{~Gy}$ of C and Ne ion beams (Figure 1). Overall, $\mathrm{C}$ and Ne seemed to have more similar dose effects than Ar radiation on RSR and all dose effect curves had a "shoulder" before they sharply fell (Figure 1).
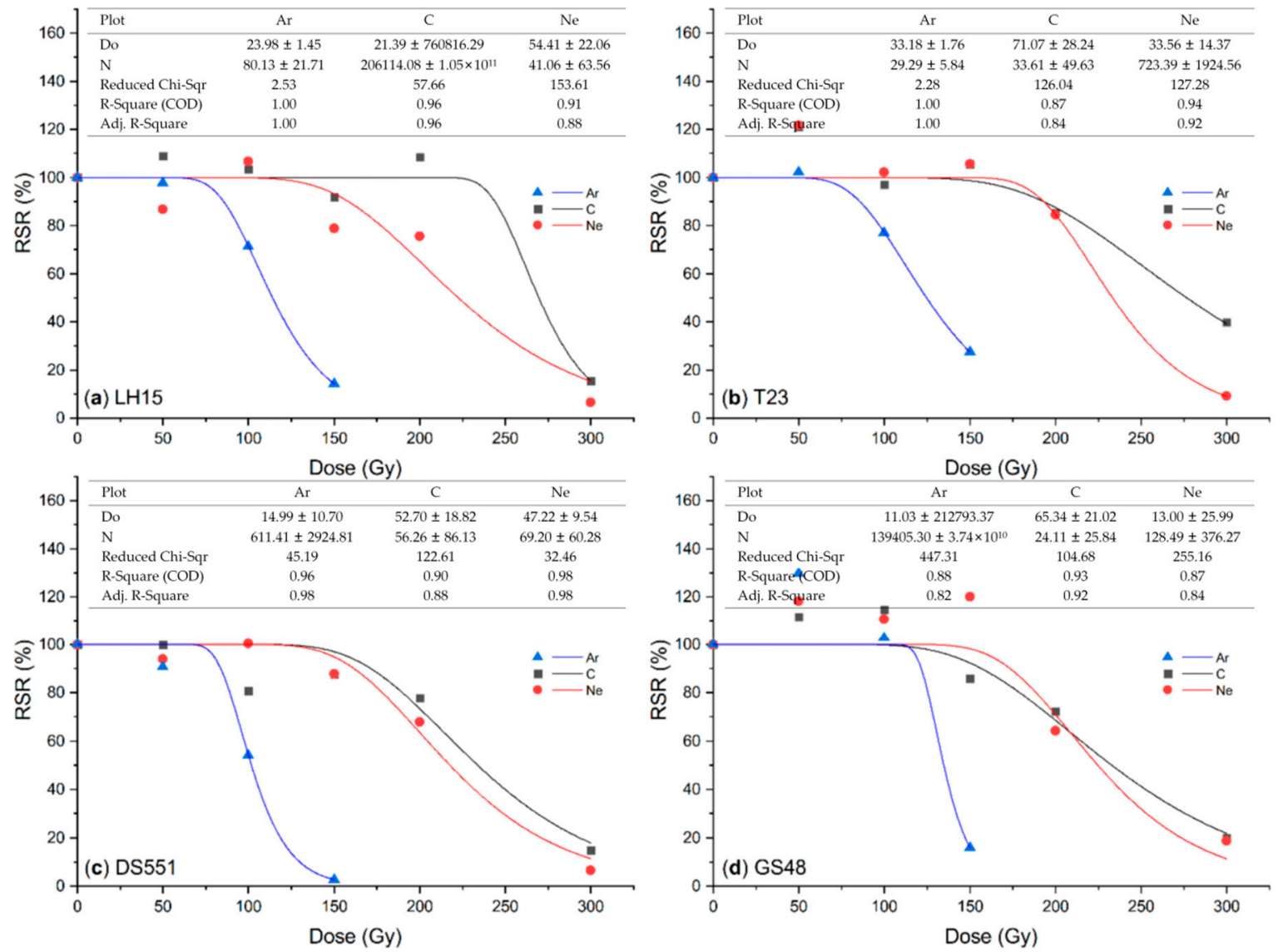

Figure 1. Relative seedling survival rate (RSR) of the $M_{1}$ seedlings from the dry seeds of rice lines (a) LH15, (b) T23, (c) DS551, and (d) GS48 irradiated with the argon (Ar), carbon (C) and neon (Ne) ion beams. RSR is present as \% of the seedling survival rate of each treatment divided by that of their respective untreated controls. Scatters are experimental data points and fitted by nonlinear curves based on a single-hit multi-target (SHMT) model [33]. The SHMT model equation is $\mathrm{S}=(1-(1-$ $\left.\exp (-\mathrm{D} / \mathrm{Do}))^{\mathrm{N}}\right) \times 100$.

Radiation also substantially reduced the seed set of $\mathrm{M}_{1}$ plants (Figure 2). Firstly, a great variation of the seed set was observed among the different panicles of a single $\mathrm{M}_{1}$ plant and among the different plants treated with the same ion beams at the same dose, which was manifested by the great standard variation of the relative seed set at each data point. Secondly, there was a tendency of decline for the seed set with the increase of radiation dose for all four genotypes. Ar again seemed to be the most effective one, with the reduction of the seed set at $150 \mathrm{~Gy}$ approaching to the same level of the other 
two at 300 Gy in most cases. Except for Ne ion radiation for DS551, the dose effect curves had no typical "shoulder", and the curves of C and Ne ion radiation were similar to each other in all four genotypes except DS551 (Figure 2).
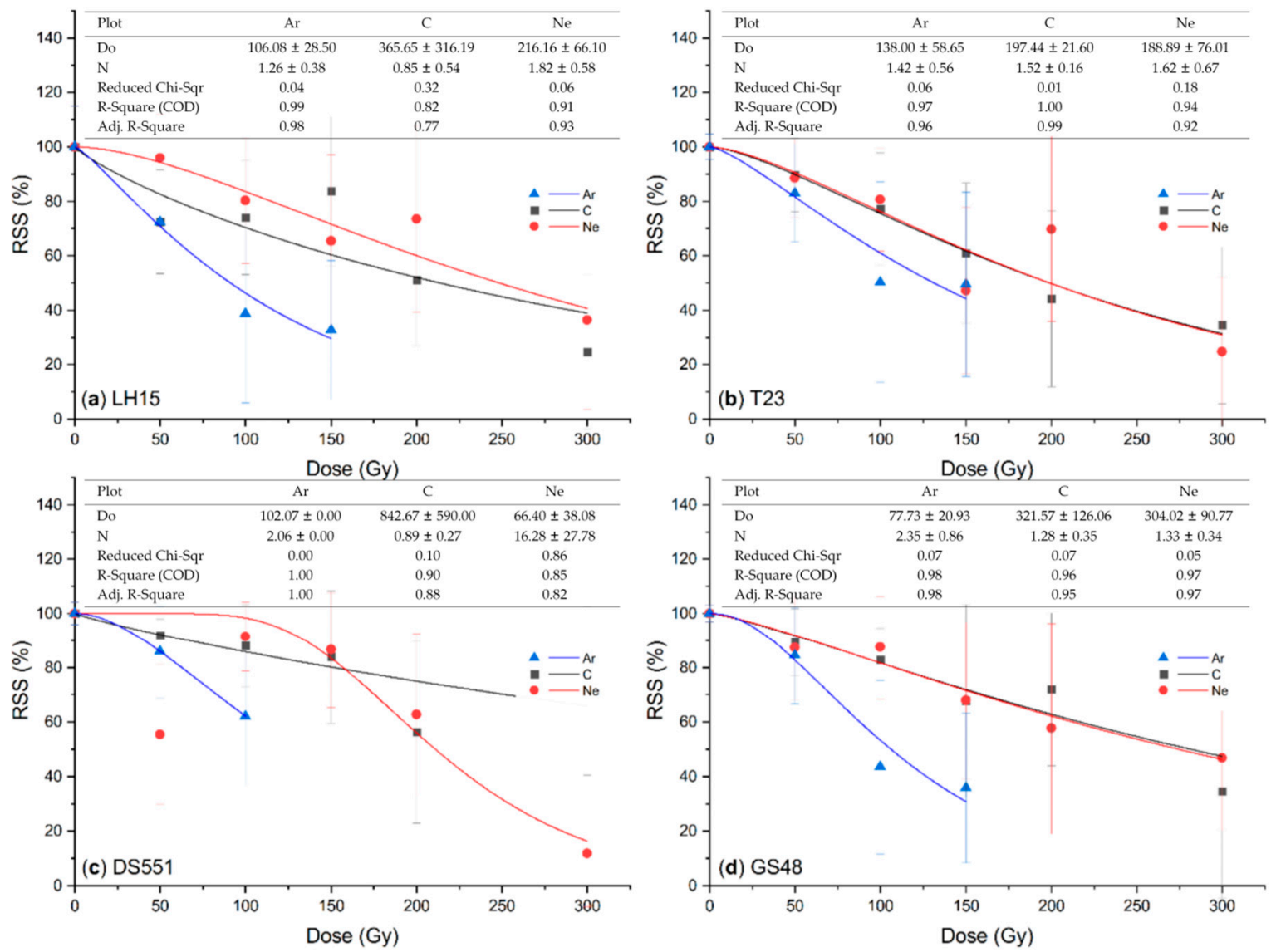

Figure 2. Relative seed set (RSS) of the $\mathrm{M}_{1}$ plants developed from the dry seeds of rice lines (a) LH15, (b) T23, (c) DS551, and (d) GS48 irradiated with the argon (Ar), carbon (C) and neon (Ne) ion beams. RSS is present as \% of the seed set of each treatment divided by that of their respective untreated controls. Data are the mean \pm standard deviation of the seed set of 10 plants. Scatters are experimental data points and fitted by nonlinear curves based on a single-hit multi-target (SHMT) model [33]. The SHMT model equation is $S=\left(1-(1-\exp (-\mathrm{D} / \mathrm{Do}))^{\mathrm{N}}\right) \times 100$.

\subsection{Morphological Mutants in $M_{2}$ Populations}

Chlorophyll (Chl)-deficient mutants (mostly albino or yellow leaf mutants) and morphological mutants (e.g., male-sterile mutants) were observed in all the $\mathrm{M}_{2}$ populations (Figures 3 and 4 ). However, there were only a limited number of the $\mathrm{M}_{2}$ plants at high doses (Ar: $150 \mathrm{~Gy}$; C and Ne: $300 \mathrm{~Gy}$ ) due to the low survival rate and low fertility of the $\mathrm{M}_{1}$ plants, hence the mutation frequencies at these doses could be over/under estimated. Similar to its effect on $\mathrm{M}_{1}$ plants, greater mutation frequencies were observed for Ar than for $\mathrm{C}$ and Ne radiation at the dose of 50 and $100 \mathrm{~Gy}$ in most cases. A few exceptions were Chl deficiency at 100 Gy for T23 (Figure 3c,d) and GS48 (Figure 3g,h), and Chl deficiency for LH15 on the $\mathrm{M}_{1}$ panicle basis (Figure $3 b$ ). At higher doses of radiation, mutation frequencies reached up to $\sim 22-37 \%$ on the $\mathrm{M}_{1}$ plant basis and $\sim 15-25 \%$ on the $\mathrm{M}_{1}$ panicle basis for both $\mathrm{Chl}$ deficiency and male sterility, but without consistent and significant ion beam/genotype/dose effect (Figures 3 and 4), though there were two specific cases where the mutation frequency increased with the increase of radiation dose, i.e., the Chl deficiency of Ne irradiated T23 (Figure 3c,d) and C irradiated DS551 (Figure 3e). 

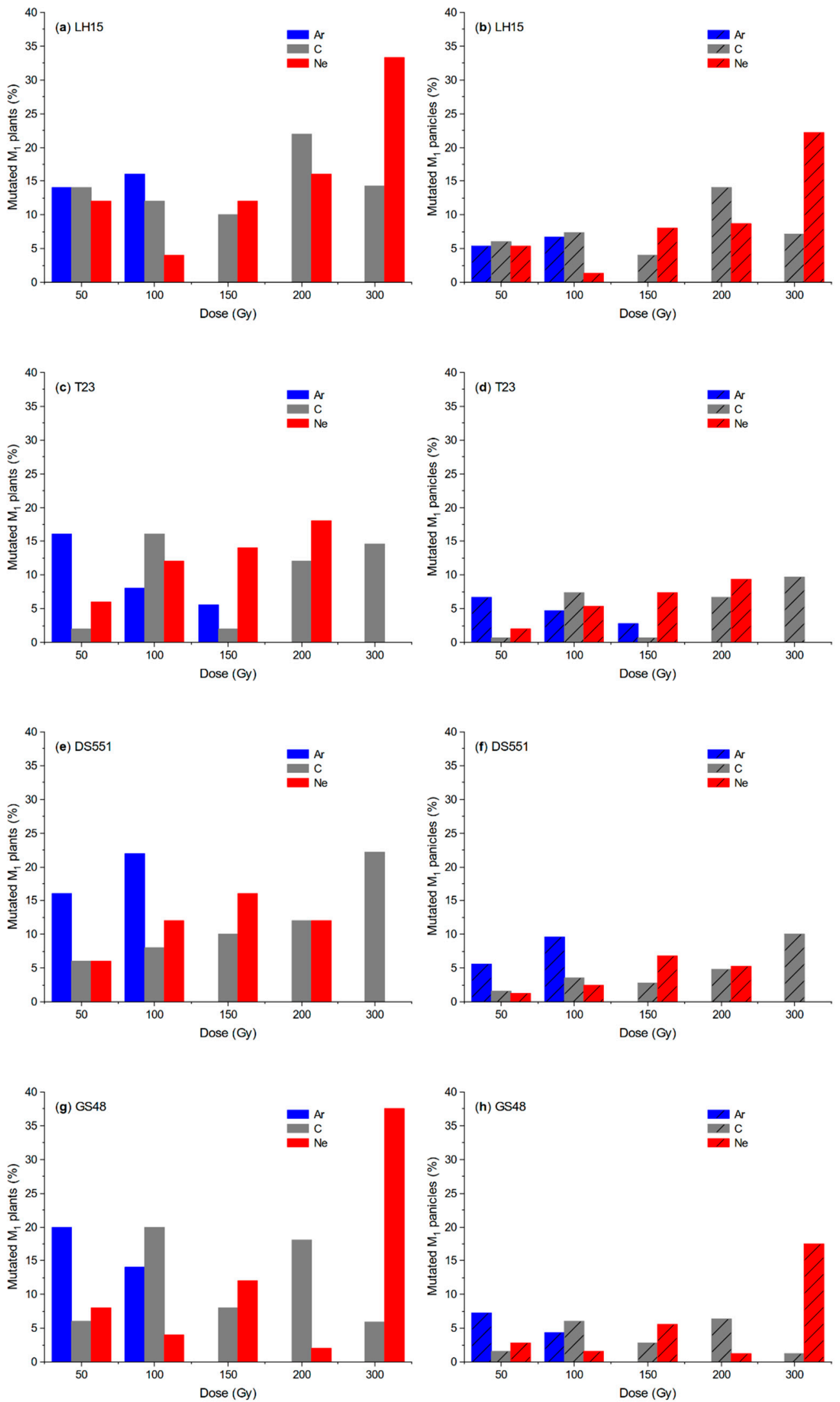

Figure 3. Frequency of chlorophyll (Chl)-deficient mutations in the $\mathrm{M}_{2}$ populations of four rice lines on the $\mathrm{M}_{1}(\mathbf{a}, \mathbf{c}, \mathbf{e}, \mathbf{g})$ plant-row and $(\mathbf{b}, \mathbf{d}, \mathbf{f}, \mathbf{h})$ the panicle-row basis. $\mathrm{M}_{1}$ plants were grown from the dry seeds irradiated with the different doses of argon (Ar), carbon (C) and neon (Ne) ion beams. Chl-deficient plants were determined during the seedling stage. 

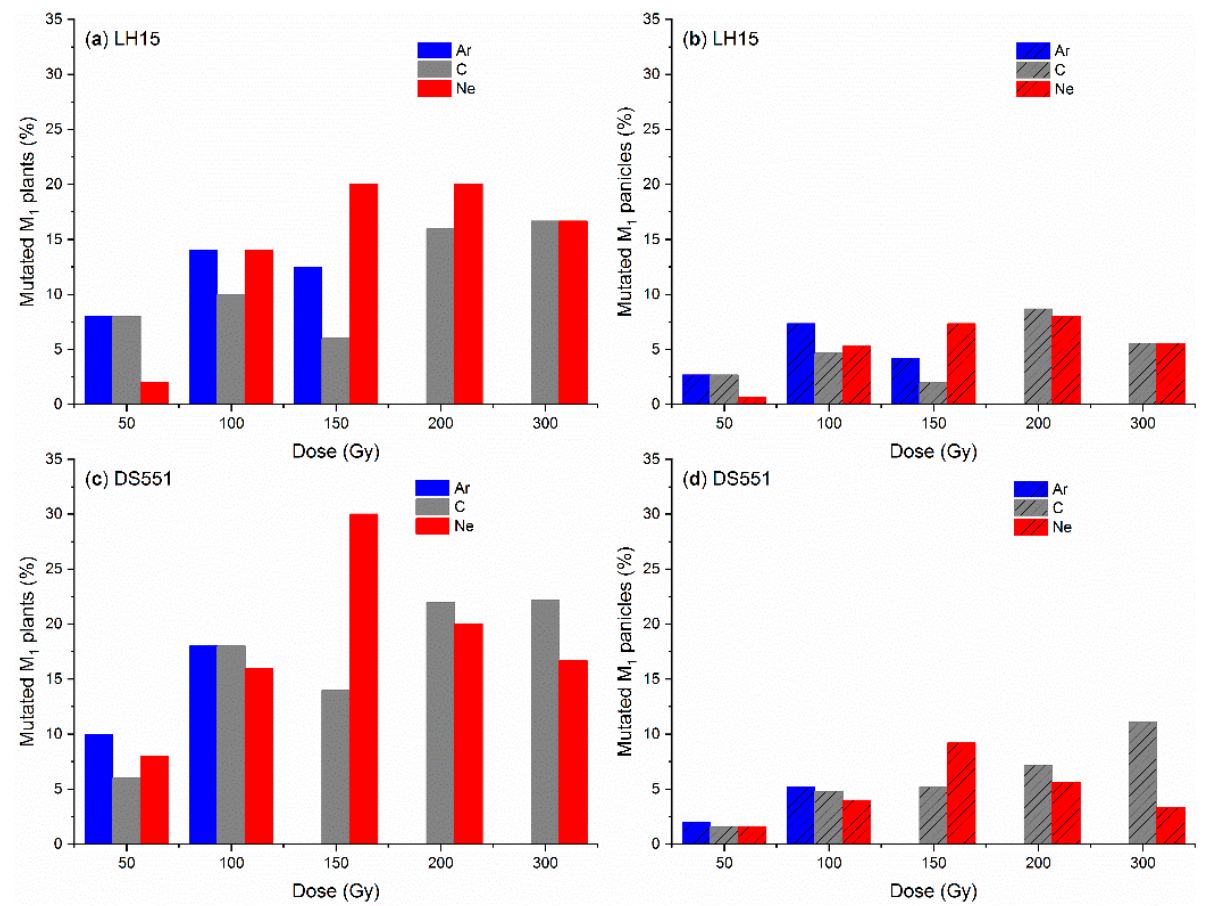

Figure 4. Frequency of male-sterile mutations in the $\mathrm{M}_{2}$ populations of the two rice lines on the $\mathrm{M}_{1}$ $(\mathbf{a}, \mathbf{c})$ plant-row and $(\mathbf{b}, \mathbf{d})$ the panicle-row basis. $\mathrm{M}_{1}$ plants were grown from the dry seeds irradiated with the different doses of argon ( $\mathrm{Ar})$, carbon $(\mathrm{C})$ and neon $(\mathrm{Ne})$ ion beams. Male-sterile plants were determined during the flowering stage.

Three and five panicles were harvested from each $\mathrm{M}_{1}$ plant for indica and japonica rice, respectively. Not all the panicles of one $\mathrm{M}_{1}$ plant had mutated $\mathrm{M}_{2}$ plants, and in most cases, only one or two panicle rows of one $\mathrm{M}_{1}$ plant had mutated plants (Figure 5). Therefore, the mutation frequencies on the panicle basis were much lower than on the plant basis for all treatments (Figures 3 and 4).
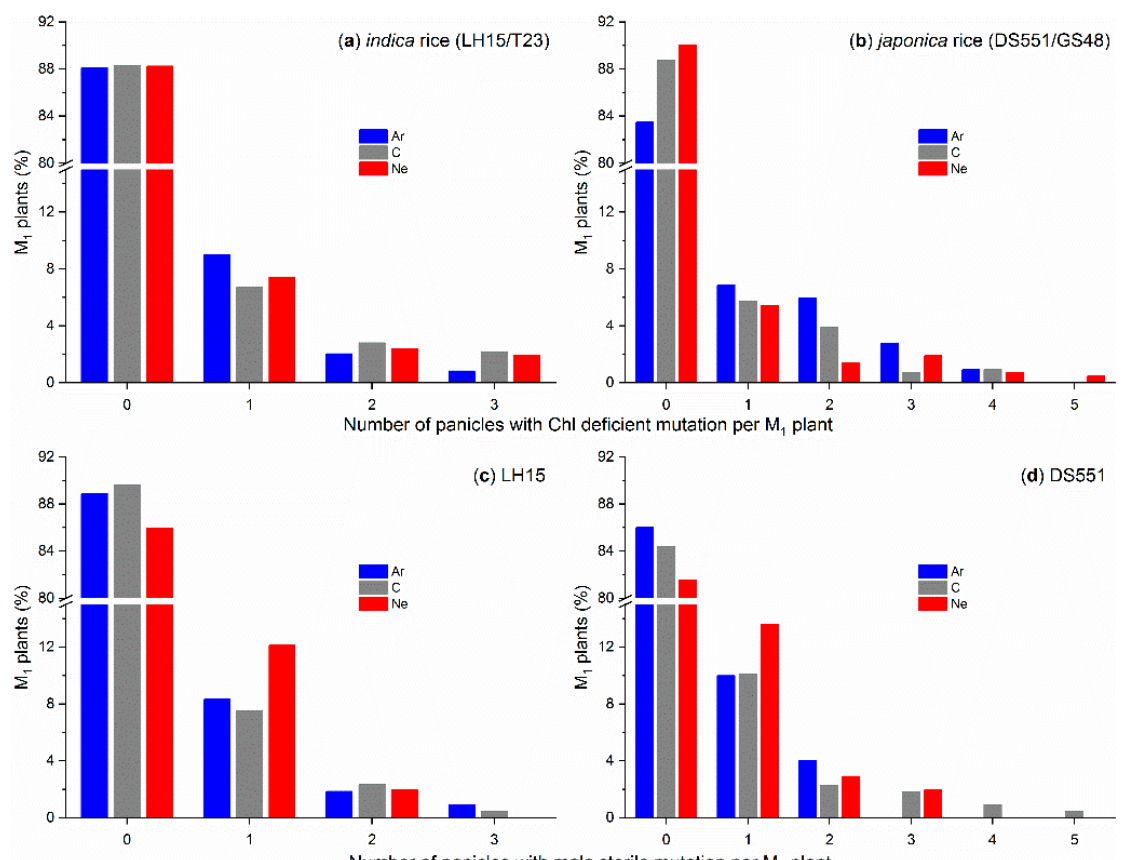

Figure 5. Frequency of the $\mathrm{M}_{1}$ plants of indica rice lines (LH15/T23) as well as the japonica rice lines (DS551/GS48) having different number of panicles with (a,b) chlorophyll (Chl)-deficient and (c,d) male-sterile 
mutation per $\mathrm{M}_{1}$ plant. $\mathrm{M}_{1}$ plants were grown from the dry seeds irradiated with the different doses of argon (Ar), carbon (C) and neon ( $\mathrm{Ne}$ ) ion beams. Chl-deficient and male-sterile plants were determined during the seedling and flowering stages, respectively. Three and five panicles were harvested from each $\mathrm{M}_{1}$ plant for the indica and japonica rice, respectively.

Plants with other mutated traits such as dwarfism were also observed in the $\mathrm{M}_{2}$ populations but with much lower frequencies than the male-sterile plants. High frequencies of dwarf mutants were observed in the $\mathrm{M}_{2}$ populations of the japonica line DS551, but almost no dwarf mutants were observed in the indica rice LH15. Both male-sterile and dwarf mutations were proven to be inheritable: progenies of dwarf plants showed the same trait in $\mathrm{M}_{3}$ and $\mathrm{M}_{4}$ progenies, while a proportion of the $\mathrm{M}_{3}$ progenies derived from the wild-type (WT) sibling plants of the $\mathrm{M}_{2}$ male-sterile plants were always male-sterile.

\subsection{Genome-wide Mutations in $M_{4}$ Plants}

A total of 137-172 million clean reads were generated per sample and when mapped to the reference Nipponbare genome, it was equivalent to a mapping rate of 95.63-98.79\% (Table 1). These reads covered $97.29-97.41 \%$ of the whole reference genome with a sequencing depth of 53.46-66.52× (Table 1). A total of 236-453 SBSs and InDels were identified in the six $\mathrm{M}_{4}$ mutant plants, with more SBSs than InDels in all the plants (Table 2)

Table 1. Statistics of the Illumina HiSeq whole genome-sequencing data of DS551 and its six $\mathrm{M}_{4}$ mutant plants from the three ion beam radiations.

\begin{tabular}{ccccc}
\hline Material $^{\mathbf{1}}$ & No. of Mapped Reads & Mapping Rate (\%) & Genome Coverage (\%) & Sequencing Depth $(\times)$ \\
\hline DS551 & $135,748,093$ & 98.79 & 97.30 & 53.46 \\
Ar_50 & $153,313,517$ & 95.63 & 97.37 & 59.82 \\
Ar_100 & $169,292,288$ & 98.47 & 97.41 & 66.52 \\
C_150 & $143,348,549$ & 98.29 & 97.29 & 55.29 \\
C_200 & $154,943,939$ & 98.18 & 97.30 & 61.15 \\
Ne_50 & $161,256,389$ & 98.67 & 97.34 & 63.27 \\
Ne_100 & $164,791,769$ & 98.16 & 97.34 & 64.84 \\
\hline
\end{tabular}

${ }^{1} \mathrm{Ar}, \mathrm{C}$ and Ne stand for argon, carbon and neon ion beams, respectively; the numbers denote the doses (Gy) applied for the mutagenic treatment.

Table 2. Number and characteristics of the mutations identified in the six $\mathrm{M}_{4}$ plants from the ion beam radiations of rice genotype DS551.

\begin{tabular}{|c|c|c|c|c|c|}
\hline \multirow[b]{2}{*}{ Mutant $^{1}$} & \multirow[b]{2}{*}{ Total } & \multicolumn{2}{|c|}{ Single Base Substitution (SBS) } & \multicolumn{2}{|c|}{ Insertion/Deletion (InDel) } \\
\hline & & Subtotal (Ti/Tv) ${ }^{2}$ & $\begin{array}{c}\text { Ex. (Syn/Nonsyn } \\
\text { /Stop-Gain/Loss) }^{3}\end{array}$ & Subtotal & $\begin{array}{c}\text { Ex. (Frame-/Nonframe } \\
\text {-Shift/Stop-Gain/Loss) }\end{array}$ \\
\hline Ar_50 & 236 & $205(141 / 64)$ & $6(2 / 4 / 0 / 0)$ & 31 & $0(0 / 0 / 0 / 0)$ \\
\hline Ar_100 & 453 & $404(297 / 107)$ & $2(1 / 1 / 0 / 0)$ & 49 & $0(0 / 0 / 0 / 0)$ \\
\hline C_150 & 256 & $223(139 / 84)$ & $5(1 / 4 / 0 / 0)$ & 33 & $0(0 / 0 / 0 / 0)$ \\
\hline C_200 & 269 & $228(145 / 83)$ & $5(1 / 4 / 0 / 0)$ & 41 & $1(1 / 0 / 0 / 0)$ \\
\hline Ne_50 & 307 & $275(156 / 119)$ & $0(0 / 0 / 0 / 0)$ & 32 & $0(0 / 0 / 0 / 0)$ \\
\hline $\mathrm{Ne} \_100$ & 238 & $197(128 / 69)$ & $2(2 / 0 / 0 / 0)$ & 41 & $1(1 / 0 / 0 / 0)$ \\
\hline
\end{tabular}

${ }^{1} \mathrm{Ar}, \mathrm{C}$ and Ne stand for argon, carbon and neon ion beams, respectively; the numbers denote the doses (Gy) applied for the mutagenic treatment; ${ }^{2} \mathrm{Ti} / \mathrm{Tv}$ : transition (C:G>T:A and T:A>C:G)/transversion (C:G>A:T, C:G>G:C, T:A>G:C, and T:A>A:T); ${ }^{3}$ Ex. (Syn/Nonsyn, stop-gain/loss, frame-/nonframe-shift) refers to the number of SBSs or InDels in the exonic regions that were synonymous, nonsynonymous, stop codon gain or loss, frame-shift or nonframe-shift mutations, respectively.

SBSs and InDels were distributed, not completely evenly, in all the chromosomes of the rice genome (Figure 6). There were a few peaks where more variations existed in 500-kb windows, e.g., the highest peak on the chromosome 1 of the Ne_50 plant with 35 mutations (Figure 6). Repetitive sequences were often present around centromeric regions, but these regions seemed not always to have more mutations, and indeed many peaks were in non-repetitive regions (Figure 6). 


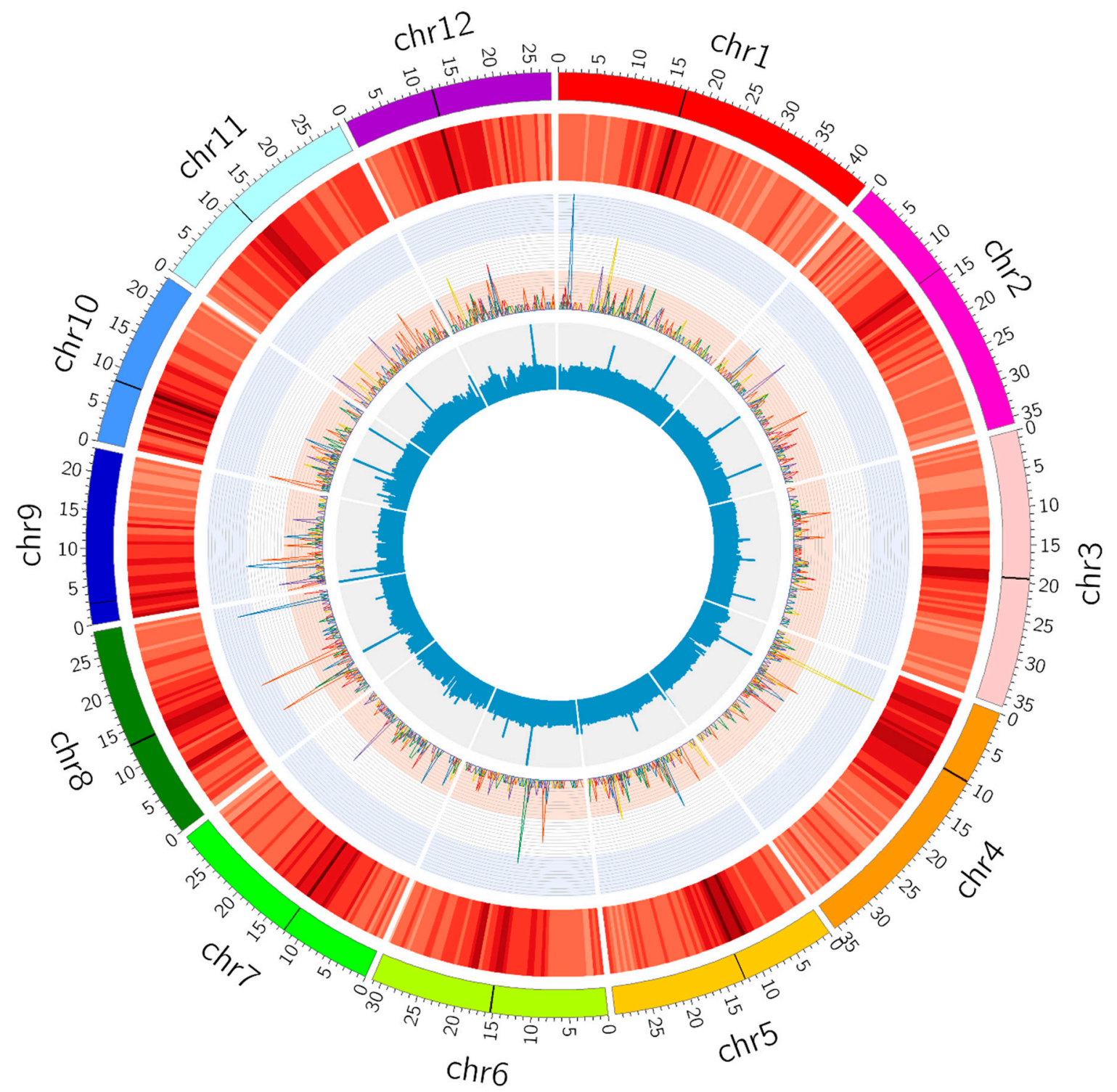

Figure 6. Genome-wide characterization of the single base substitutions (SBSs) and small insertion/deletions (InDels) in the six ion beam-mutagenized $\mathrm{M}_{4}$ rice plants. Circles from outside to inside: Twelve rice chromosomes on the 1-Mb scale with the black band standing for centromere; Heat map of the repetitive sequence contents in the rice reference genome in non-overlapping 500-kb windows, the darker the color, the higher the content, with repetitive sequence data derived from the Rice Genome Annotation Project (RGAP) release 7; Line plots of the SBS and InDel numbers in the non-overlapping 500-kb windows (the highest peak equates to 35 mutations in a 500-kb window on the chromosome 1 of the Ne_50 plant), the line colors are red for Ar_50, orange for Ar_100, yellow for C_150, green for C_200, blue for $\mathrm{Ne} \_50$, and purple for $\mathrm{Ne} \_100$, respectively; Blue histograms represent the average sequencing depth of all the rice samples in the non-overlapping 500-kb windows.

Among the six mutant plants, Ar_100 seemed to have far more SBSs and more InDels than other plants (Table 2). All six possible types of substitution were detected, with the transitions (Ti: C:G>T:A and T:A > C:G) to transversions (Tv: C:G > A:T, C:G > G:C, T:A > G:C, and T:A > A:T) ratios ranging from 1.31 (Ne_50) to 2.78 (Ar_100) (Table 2). SBSs and InDels were identified in the different genomic regions across the whole genome, but most of them were in the intergenic regions (Figure $7 \mathrm{a}, \mathrm{b}$ ). The size of the InDels varied from 1 to $50 \mathrm{bps}$, but the majority of them were 1-4 bps and more deletions were observed than insertions in all the mutant plants (Figure 7c). 

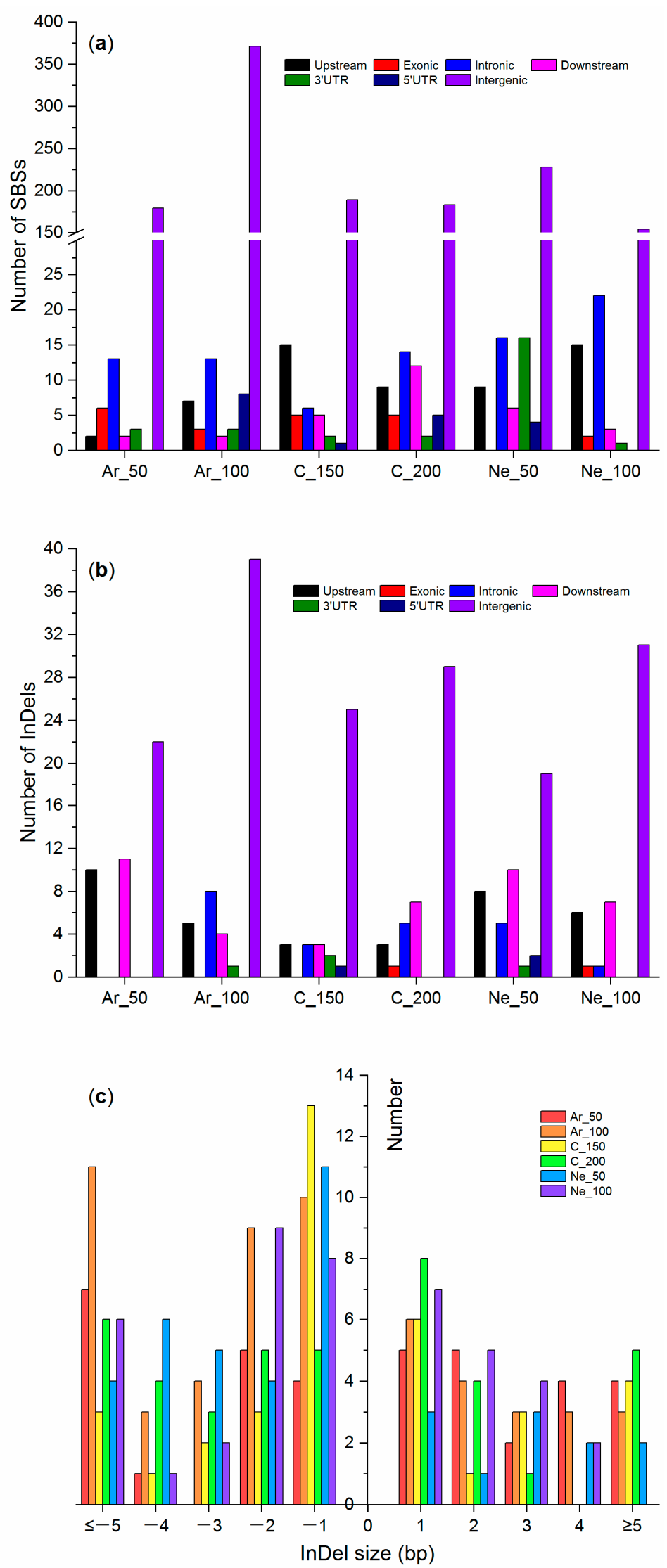

Figure 7. Numbers of (a) the single base substitutions (SBSs), (b) the insertion/deletions (InDels) located in the different genomic regions and (c) the number of InDels with different sizes in the six ion beam-mutagenized rice $\mathrm{M}_{4}$ plants. 
Only a fraction of SBSs (0-2.9\%) and InDels (0-2.4\%) were in exonic regions (Table 2). In total, only 13 SBSs and two InDels could potentially either change encoded amino acids (nonsynonymous mutations) or truncate encoded peptides (frame-shift mutations). The 13 SBSs and two InDels that could have a functional effect on the respective genes were all verified using the integrative genomics viewer (IGV) [34] (Figures S1-S15).

\section{Discussion}

High-energy ion beam radiation is a new type of physical mutagen but its application in plant breeding has not been as common as $\gamma$ rays, probably due to the limited accessibility to many plant breeders, particularly outside of Japan and China. In rice, there have been several reports on C/Ne ion beam mutagenesis and on the genetic, genomic and phenotypical characteristics of induced mutants. The present study not only evaluated the mutagenic effect of a new ion beam $\left({ }^{40} \mathrm{Ar}^{18+}\right)$ in parallel with $\mathrm{C}$ and Ne beams on rice from breeding perspectives, but also identified and characterized the mutations in advanced lines using whole genome sequencing. The findings of the present study hence have important implications to rice ion beam radiation breeding.

\subsection{Ar, C and Ne Ion Beams Could All Be Used for Mutation Induction and Breeding in Rice}

Ion beam radiation differs from $\gamma$ rays because of its far greater LETs. The greater the LET, the more localized and denser ionizations would be produced in a cell, which could cause more DNA damages [1]. Although the LET of the Ar ion beam is about three and seven times more than that of $\mathrm{C}$ and Ne beams (Table 3), they all seemed to be effective for mutation induction when a suitable dose was applied. The dose curves of the seedling survival rates of $\mathrm{M}_{1}$ plants showed that there were "shoulder" doses where radiation showed no or limited negative effects, e.g., 50-150 Gy for C and Ne ion beams (Figure 1). Furthermore, a big shoulder of fitting curves occurred under low LET (C, Ne ion beams), whereas the shoulder became small with the increase of LET (Ar ion beams) (Table 3; Figure 1). A similar phenomenon was also presented in the survival curves of multicellular spheroids fitted by a single-hit multi-target (SHMT) model [33]. However, no such "shoulder" dose existed for the seed set except for the Ne ion beam radiation of DS551 (Figure 2), suggesting that the biological basis of radiation on growth and reproduction might be different. Based on these dose effect curves, we recommend that the doses for $\mathrm{Ar}, \mathrm{C}$ and Ne radiation to be 100, 200 and $200 \mathrm{~Gy}$, respectively. When the dry seeds were treated with ion beams using the above recommended doses, $50 \%$ relative seedling survival rate and seed set were achieved for most rice genotypes (Figures 1 and 2).

Table 3. Characteristics of the ion beams used for the rice seed irradiation.

\begin{tabular}{ccccc}
\hline Ion Beam & Energy $(\mathbf{M e V} / \mathbf{u})$ & LET $^{\mathbf{1}}(\mathbf{k e V} / \boldsymbol{\mu m})$ & Doses $(G y)$ & Dose Rate $(G y / M i n)$. \\
\hline${ }^{40} \mathrm{Ar}^{18+}$ & 500 & 92 & $50,100,150,200,300$ & 7.1 \\
${ }^{12} \mathrm{C}^{6+}$ & 290 & 13 & $50,100,150,200,300$ & 7.7 \\
${ }^{20} \mathrm{Ne}^{10+}$ & 400 & 31 & $50,100,150,200,300$ & 5.5 \\
\hline
\end{tabular}

${ }^{1}$ LET: linear energy transfer.

At the phenotypical level, relative high mutation rates were achieved for all radiation in all four genotypes. The Chl deficiency mutation rates were similar to those reported by Yamaguchi et al. [3] on the $\mathrm{M}_{1}$ plant basis, e.g., about $8-15 \%$ for the two $\mathrm{C}$ and one He ion beam radiation at doses that attained $50-90 \%$ seedling survival rates. Similarly, the high mutation frequencies of male-sterile plants were observed in the populations of two rice lines, further demonstrating the effectiveness of these three ion beams for the mutation induction in rice. No previous studies had data of morphological mutations at a mature stage, hence they could not be compared directly with other studies on ion beam radiation in rice.

At the genomic level, the Ar_100 plant had substantially more SBSs and InDels than the other plants treated with other ion beams or doses (Table 2). However, the mutational impacts seemed to 
be not that different from each other, because the numbers of exonic mutation in the six plants were indeed quite similar (Table 2).

\subsection{How to Make Full Use of Irradiated Seeds?}

Compared with $\gamma$ rays, ion beam radiation is not only far more expensive, but also far less available and accessible to plant breeders. Every irradiated seed is very precious and thus it is of paramount importance for plant researchers to make full use of mutagenized seeds in their programs.

Panicles are differentiated from shoot apex meristem (SAM), however, it is not yet known whether there is a progenitor cell or cells already in a mature seed, which will be eventually developed into panicles. If all panicles of a plant were developed from a single common progenitor cell in a seed, then all the panicles would carry the same mutations induced by the ion beam radiation. If there was more than one progenitor cell, different panicles could have different mutations. In the present study, we observed that among the five or three panicle rows of a $\mathrm{M}_{1}$ plant, most plants had one or two panicle rows with mutated seedlings at the seedling stage or mutated plants at the later stages (Figure 5), suggesting that different panicles are highly likely to be from different progenitor cells in seeds.

Based on the proportion of $\mathrm{M}_{1}$ plants with different numbers of panicles with mutations (Figure 5) and the probability analysis of different scenarios with one to six progenitor cells, each producing two or three panicles, it was reasoned that there were three to four progenitor cells in the two indica lines (with fewer panicles per plant) and four to five in the two japonica lines. Therefore, to make full use of the ion beam irradiated seeds for mutation breeding, $\mathrm{M}_{2}$ seeds should be harvested from all the panicles of the $\mathrm{M}_{1}$ plants because they could all carry different induced mutations.

\subsection{Mutations Identified via Genome/Exome Sequencing}

During the past 10 years, several studies have investigated genome-wide mutations induced by ion beams in rice and other plant species. In rice, Ichida et al. [29] investigated genome-wide mutations induced by $\mathrm{C}$ and $\mathrm{Ne}$ ion beams using exome sequencing of randomly selected $\mathrm{M}_{2}$ plants, while $\mathrm{Li}$ et al. [30] and Yang et al. [31] sequenced whole genomes of stable mutant lines at the generation of $\mathrm{M}_{4}-\mathrm{M}_{6}$ for the comparison of the mutations induced by $\mathrm{C}$ ion beams and $\gamma$ rays. The overall results of these studies were consistent with the present study in terms of the type of induced mutations and their genome-wide distribution. For the quantitative analysis of the number of mutations, however, the present study can only be compared with those of Li et al. [30] and Yang et al. [31]. Due to the differences of materials and method used, the present study cannot be compared with Ichida et al. [29].

$\mathrm{Li}$ et al. [30] sequenced seven $\mathrm{M}_{5}$ lines of a japonica rice Hitomebore irradiated with $30 \mathrm{~Gy}{ }^{12} \mathrm{C}^{6+}$ beams (LET: $107 \mathrm{keV} / \mu \mathrm{m}$ ). On average, $43.7 \mathrm{SBSs}, 13.6$ deletions and 5.3 insertions were detected in each mutant. Yang et al. [31] sequenced six (four $\mathrm{M}_{4}$, two $\mathrm{M}_{5}$ ) mutants of an indica rice R173 treated with $80 \mathrm{~Gy}{ }^{12} \mathrm{C}^{6+}$ beams (LET: $50 \mathrm{keV} / \mu \mathrm{m}$ ). On average, $30.3 \mathrm{SBSs}$ (including multiple nucleotide variants) and 10 InDels were observed for each of the four $\mathrm{M}_{4}$ mutant plants. In the present study, about 3-4 times more SBSs and InDels were observed in the $\mathrm{M}_{4}$ plants irradiated with 150-200 Gy of $C$ ion radiation (Table 2). This discrepancy could be partially explained by the higher radiation doses applied in the present study, and partially by other factors such as the different varieties used in different studies.

Methodologically, the present study not only excluded background mutations by removing mutations common to any two plants, but also minimized false positives by having the mutations identified by three different bioinformatic tools (Figure 8). As further confirmed by using the IGV program [34], the identified mutations were high likely to be true, though we did not verify them via wet experiment. 


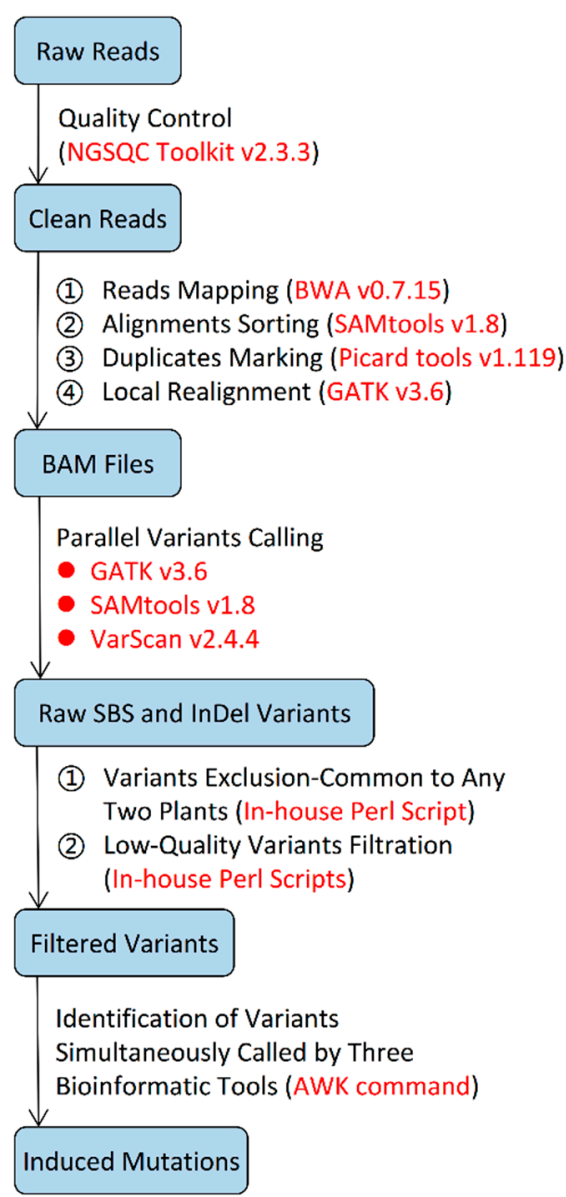

Figure 8. The pipeline used for the identification of the mutations induced by the three ion beams in the rice plants based on their whole genome-sequencing data. Blue box: Input/Output data; The actions taken and corresponding bioinformatic tools/scripts/Linux commands (highlighted by red color) used are presented for each step.

Due to its high LET nature, ion beam radiation is expected to generate SVs [1]. SVs were demonstrated in Arabidopsis in earlier studies [24,27]. Recently, SVs have also been identified in rice [29,30], though no SV was identified by Yang et al. [31] in their study. We also expect SVs to be present in the mutant plants developed in the present study and will perform detailed analysis separately.

\section{Materials and Methods}

\subsection{Irradiation of Ion Beams and Mutant Development}

The dried seeds of two indica (LH15 and T23) and two japonica (DS551 and GS48) rice lines were irradiated with $\mathrm{Ar}, \mathrm{C}$ and $\mathrm{Ne}$ ion beams with 5 doses and different dose rates (Table 3) in the Heavy-Ion Medical Accelerator in Chiba (HIMAC) Facility at the National Institute of Radiological Science, Japan.

In October 2013, the irradiated seeds $\left(\mathrm{M}_{1}\right)$ were sown together with the unirradiated controls. The survived $\mathrm{M}_{1}$ seedlings and their control ones were individually transplanted in a paddy field in the Winter Breeding Nursery of Zhejiang University in Lingshui, Hainan Province. At the seedling stage, the seedling survival rate was examined, and at mature stage, $10 \mathrm{M}_{1}$ rice plants were randomly selected for the measurement of plant height and the number of tillers per plant. Seed set rates were assessed by the analysis of two panicles from each of the $10 \mathrm{M}_{1}$ plants per treatment and respective controls. $\mathrm{M}_{2}$ seeds were harvested from individual $\mathrm{M}_{1}$ plants on a panicle (three panicles per plant for 
the two indica lines and five for the two japonica ones) and plant basis. Nonlinear dose-effect curves were drawn by fitting the experimental data with the SHMT model [33].

In 2014, $\mathrm{M}_{2}$ seeds were sown on a panicle and plant basis in the experimental paddy field of Jiaxing Academy of Agricultural Science, Zhejiang Province. Chl-deficient (albino or yellow) and male-sterile mutants are well-known to be the most common phenotypical mutations; hence they were investigated as representative traits for the assessment of the mutagenic effect. At the seedling stage, Chl-deficient mutants were observed on panicle basis at the seedling stage within two weeks after sowing. Thirty-six survived seedlings per panicle were transplanted and grown into $\mathrm{M}_{2}$ populations in panicle rows. From the flowering to the mature stage, the plants showing male sterility and/or dwarfism were recorded as putative mutants. For each panicle row with putative mutant plants, $8 \mathrm{WT}$ and 5 putative mutant $\mathrm{M}_{2}$ plants were harvested on plant basis. In the following year, $\mathrm{M}_{3}$ seeds were grown into plant rows and the respective mutant phenotype was again observed. Once the mutant phenotype was confirmed, $M_{3}$ plants were harvested as done in $\mathrm{M}_{2}$ and further grown into $\mathrm{M}_{4}$ populations as in $\mathrm{M}_{3}$ in the experimental farm of Zhejiang Zhijiang Seed Co. in Yuhang, Hangzhou, Zhejiang Province.

To examine the induced mutation at a molecular level, six $\mathrm{M}_{4}$ mutant plants of DS551, two each from $\mathrm{Ar}, \mathrm{C}$ and $\mathrm{Ne}$ ion beam radiation, were selected as representatives for the whole genome sequencing. They were designated as following: Ar_50, Ar_100, C_150, C_200, Ne_50, Ne_100 for the mutated plants according to the type of ion beams and the doses applied, respectively (Table 1). One control rice plant developed from the same progenitor DS551 plant as the mutant plants over the course was also used for sequencing.

\subsection{Genome Sequencing}

The genomic DNA of the WT and six mutant plants were extracted from flag leaf tissues at the flowering stage and fragmented to about 350 bps by a DNA ultrasonic disruptor for the construction of sequencing libraries according to the manufacturer's instructions (Covaris, Massachusetts, MA, USA). Short paired-end (PE) reads (150 bps) were generated using the Illumina HiSeq 4000 sequencing platform by Novogene Bioinformatics Technology Co., Ltd. (Beijing, China). Raw reads were pre-processed and deposited in the National Center for Biotechnology Information (NCBI) (BioProject ID: PRJNA594450).

\subsection{Mutation Detection and Annotation}

The overall process of mutation detection pipelines is presented in Figure 8. Raw PE reads were filtered using the NGSQCToolkit v 2.3.3 [35], where the cut-off value for PHRED quality score was set to be 20 and for the percentage of read length to be 70 . The filtered data were then mapped to the reference Nipponbare genome [36] using the BWA v 0.7.15 [37] with default settings. Subsequently, Sequence Alignment/Map (SAM) files were created for each plant. SAM files were further converted into binary SAM (BAM) files and sorted using the SAMtools v 1.8 [38]. Moreover, PCR duplicates were marked by MarkDuplicates in Picard tools v 1.119 [39], and the coverage and average depth of the reads were calculated using the SAMtools v 1.8 [38], together with an in-house Perl script [40].

The BAM files were further aligned for variation detection using the GenomeAnalysisTK (GATK) v 3.6 [41]. The local realignment of the reads around InDels was performed by using the module InDelRealigner in GATK [41]. The raw SBS and InDel variants were called by inputting the realigned BAM files, respectively, into the module UnifiedGenotyper in GATK [41], SAMtools v 1.8 [38], and the VarScan v 2.4.4 [42] with default parameters. The raw variants were divided into SBSs and InDels using the module SelectVariants in GATK [41]. To exclude possible background mutations, SBSs and InDels common to any two plants were excluded using an in-house Perl script [43].

The variants identified through the above process were further filtered by an in-house Perl script [44-46] according to the different bioinformatic tools to remove variants that did not pass "read depth $\geq 10$ \&\& read depth $\leq 100$ \&\& allele frequency $\geq 0.25$ ". Then, the SBSs and InDels identified 
by the above three bioinformatic tools were compared using the AWK commands and only the common variants were ultimately recorded as induced mutations and kept in the GATK VCF format (those only identified by one or two tools were excluded).

The variations identified above were annotated by ANNOVAR [47] and their genomic distribution was visualized by the Circos program [48]. The validation of the variations was performed using an IGV [34,49].

\section{Conclusions}

The present study demonstrated that ${ }^{40} \mathrm{Ar}^{18+},{ }^{12} \mathrm{C}^{6+}$ and ${ }^{20} \mathrm{Ne}^{10+}$ beams could all effectively induce mutations in rice. When proper doses were used, all ion beam radiation are expected to achieve similar high-mutation frequencies. Multiple panicles should be harvested for the development of $\mathrm{M}_{2}$ populations with a desired size from the limited number of irradiated seeds. Genome-wide genetic variations of SBSs and InDels were still present in the $\mathrm{M}_{4}$ plants, which demonstrated the mutagenic effect of the ion beams on one hand and suggests non-target mutations exist in selected mutants on the other hand.

Supplementary Materials: The following are available online at http://www.mdpi.com/2223-7747/9/5/551/s1, Figure S1: Collapsed (above) and expanded (below) visualization of the single base substitution at the position of 33,432,582 of Chromosome 2 with $C$ to T mutation (ratio of mutant allele =1.00) in Ar_100 rice plant, Figure S2: Collapsed (above) and expanded (below) visualization of the single base substitution at the position of $34,459,733$ of Chromosome 4 with G to A mutation (ratio of mutant allele $=1.00$ ) in C_150 rice plant, Figure S3: Collapsed (above) and expanded (below) visualization of the single base substitution at the position of 11,795,998 of Chromosome 6 with G to T mutation (ratio of mutant allele $=0.94$ ) in C_150 rice plant, Figure S4: Collapsed (above) and expanded (below) visualization of the single base substitution at the position of 1,950,599 of Chromosome 12 with A to T mutation (ratio of mutant allele $=1.00$ ) in C_150 rice plant, Figure S5: Collapsed (above) and expanded (below) visualization of the single base substitution at the position of 4,402,323 of Chromosome 3 with $\mathrm{G}$ to A mutation (ratio of mutant allele $=1.00$ ) in C_200 rice plant, Figure S6: Collapsed (above) and expanded (below) visualization of the single base substitution at the position of $25,928,670$ of Chromosome 4 with $C$ to $T$ mutation (ratio of mutant allele $=1.00$ ) in C_200 rice plant, Figure S7: Collapsed (above) and expanded (below) visualization of the single base substitution at the position of 25,928,671 of Chromosome 4 with $\mathrm{C}$ to $\mathrm{T}$ mutation (ratio of mutant allele $=1.00$ ) in C_200 rice plant, Figure S8: Collapsed (above) and expanded (below) visualization of the deletion at the position of 522,579-522,584 of Chromosome 12 with GGCGCC to G mutation (ratio of mutant allele $=1.00$ ) in C_200 rice plant, Figure S9: Collapsed (above) and expanded (below) visualization of the single base substitution at the position of 15,210,317 of Chromosome 7 with C to A mutation (ratio of mutant allele = 0.57) in Ar_50 rice plant, Figure S10: Collapsed (above) and expanded (below) visualization of the single base substitution at the position of 21,193,688 of Chromosome 8 with C to G mutation (ratio of mutant allele $=0.44$ ) in Ar_50 rice plant, Figure S11: Collapsed (above) and expanded (below) visualization of the single base substitution at the position of 3,176,338 of Chromosome 12 with A to C mutation (ratio of mutant allele = 0.29) in Ar_50 rice plant, Figure S12: Collapsed (above) and expanded (below) visualization of the single base substitution at the position of 3,176,347 of Chromosome 12 with G to A mutation (ratio of mutant allele = 0.31) in Ar_50 rice plant, Figure S13: Collapsed (above) and expanded (below) visualization of the single base substitution at the position of 25,423,413 of Chromosome 1 with C to T mutation (ratio of mutant allele $=0.37$ ) in C_150 rice plant, Figure S14: Collapsed (above) and expanded (below) visualization of the single base substitution at the position of $7,704,982$ of Chromosome 5 with T to $\mathrm{G}$ mutation (ratio of mutant allele $=0.54$ ) in C_200 rice plant, Figure S15: Collapsed (above) and expanded (below) visualization of the deletion at the position of 22,189,053-22,189,055 of Chromosome 7 with CGA to C mutation (ratio of mutant allele $=0.52$ ) in Ne_100 rice plant.

Author Contributions: Conceptualization, Q.S., J.H. and L.Z.; methodology, Y.Z., S.L., L.Z. and Y.F.; software, Y.Z.; validation, Y.Z. and S.L.; formal analysis, Y.Z. and S.L.; investigation, S.L., H.F. and Y.Z.; resources, H.F., L.Z. and Y.F.; data curation, Q.S., J.H., H.F. and L.Z.; writing-original draft preparation, Y.Z. and S.L.; writing一review and editing, Q.S., J.H., H.F. and L.Z.; visualization, Y.Z.; supervision, and funding acquisition, Q.S. All authors have read and agreed to the published version of the manuscript.

Funding: This research was supported by grants from the National Key Research and Development Program of China (2016YFD0102103), the National Natural Science Foundation of China (No. 11275171), and the FNCA project on Mutation Breeding.

Acknowledgments: The authors are grateful to Takashi Shimokawa of HIMAC for his assistance on ion beam radiation.

Conflicts of Interest: The authors declare no conflict of interest. 


\section{References}

1. Abe, T.; Ryuto, H.; Fukunishi, N. Ion beam radiation mutagenesis. In Plant Mutation Breeding and Biotechnology, 1st ed.; Shu, Q.Y., Forster, B.P., Nakagawa, H., Eds.; Plant Breeding and Genetics Section, Joint FAO/IAEA Division of Nuclear Techniques in Food and Agriculture, International Atomic Energy Agency: Vienna, Austria, 2012; Chapter 9; pp. 99-106.

2. Tanaka, A.; Shikazono, N.; Hase, Y. Studies on biological effects of ion beams on lethality, molecular nature of mutation, mutation rate, and spectrum of mutation phenotype for mutation breeding in higher plants. J. Radiat. Res. 2010, 51, 223-233. [CrossRef] [PubMed]

3. Yamaguchi, H.; Hase, Y.; Tanaka, A.; Shikazono, N.; Degi, K.; Shimizu, A.; Morishita, T. Mutagenic effects of ion beam irradiation on rice. Breed. Sci. 2009, 59, 169-177. [CrossRef]

4. Ishikawa, S.; Ishimaru, Y.; Igura, M.; Kuramata, M.; Abe, T.; Senoura, T.; Hase, Y.; Arao, T.; Nishizawa, N.K.; Nakanishi, H. Ion-beam irradiation, gene identification, and marker-assisted breeding in the development of low-cadmium rice. Proc. Natl. Acad. Sci. USA 2012, 109, 19166-19171. [CrossRef] [PubMed]

5. Takano, N.; Takahashi, Y.; Yamamoto, M.; Teranishi, M.; Yamaguchi, H.; Sakamoto, A.N.; Hase, Y.; Fujisawa, H.; $\mathrm{Wu}$, J.; Matsumoto, T.; et al. Isolation of a novel UVB-tolerant rice mutant obtained by exposure to carbon-ion beams. J. Radiat. Res. 2013, 54, 637-648. [CrossRef] [PubMed]

6. Ichitani, K.; Yamaguchi, D.; Taura, S.; Fukutoku, Y.; Onoue, M.; Shimizu, K.; Hashimoto, F.; Sakata, Y.; Sato, M. Genetic analysis of ion-beam induced extremely late heading mutants in rice. Breed. Sci. 2014, 64, $222-230$. [CrossRef] [PubMed]

7. Sevanthi, A.M.V.; Kandwal, P.; Kale, P.B.; Prakash, C.; Ramkumar, M.K.; Yadav, N.; Mahato, A.K.; Sureshkumar, V.; Behera, M.; Deshmukh, R.K.; et al. Whole genome characterization of a few EMS-induced mutants of upland rice variety Nagina 22 reveals a staggeringly high frequency of SNPs which show high phenotypic plasticity towards the wild-type. Front. Plant Sci. 2018, 9, 1179. [CrossRef]

8. Hussain, M.; Iqbal, M.A.; Till, B.J.; Rahman, M.U. Identification of induced mutations in hexaploid wheat genome using exome capture assay. PLoS ONE 2018, 13, e0201918. [CrossRef]

9. Li, W.J.; Guo, H.J.; Wang, Y.B.; Xie, Y.D.; Zhao, L.S.; Gu, J.Y.; Zhao, S.R.; Zhao, B.C.; Wang, G.J.; Liu, L.X. Identification of novel alleles induced by EMS-mutagenesis in key genes of kernel hardness and starch biosynthesis in wheat by TILLING. Genes Genom. 2017, 39, 387-395. [CrossRef]

10. Sidhu, G.; Mohan, A.; Zheng, P.; Dhaliwal, A.K.; Main, D.; Gill, K.S. Sequencing-based high throughput mutation detection in bread wheat. BMC Genomics 2015, 16, 962. [CrossRef]

11. Sun, J.; Luu, N.S.; Chen, Z.; Chen, B.; Cui, X.; Wu, J.; Zhang, Z.; Lu, T. Generation and characterization of a Foxtail Millet (Setaria italica) mutant library. Front. Plant Sci. 2019, 10, 369. [CrossRef]

12. Mestanza, C.; Riegel, R.; Vásquez, S.C.; Veliz, D.; Cruz-Rosero, N.; Canchignia, H.; Silva, H. Discovery of mutations in Chenopodium quinoa Willd through EMS mutagenesis and mutation screening using pre-selection phenotypic data and next-generation sequencing. J. Agric. Sci. 2018, 156, 1196-1204. [CrossRef]

13. Jiao, Y.; Burke, J.; Chopra, R.; Burow, G.; Chen, J.; Wang, B.; Hayes, C.; Emendack, Y.; Ware, D.; Xin, Z. A sorghum mutant resource as an efficient platform for gene discovery in grasses. Plant Cell 2016, 28, 1551-1562. [CrossRef] [PubMed]

14. Shirasawa, K.; Hirakawa, H.; Nunome, T.; Tabata, S.; Isobe, S. Genome-wide survey of artificial mutations induced by ethyl methanesulfonate and gamma rays in tomato. Plant Biotechnol. J. 2016, 14, 51-60. [CrossRef] [PubMed]

15. García, A.; Aguado, E.; Parra, G.; Manzano, S.; Martínez, C.; Megías, Z.; Cebrián, G.; Romero, J.; Beltrán, S.; Garrido, D.; et al. Phenomic and genomic characterization of a mutant platform in Cucurbita pepo. Front. Plant Sci. 2018, 9, 1049. [CrossRef] [PubMed]

16. Elhiti, M.; Wang, H.Y.; Austin, R.S.; Chen, B.; Brown, D.; Wang, A.M. Generation of chemically induced mutations using in vitro propagated shoot tip tissues for genetic improvement of fruit trees. Plant Cell Tissue Organ Cult. 2016, 124, 447-452. [CrossRef]

17. Mohd-Yusoff, N.F.; Ruperao, P.; Tomoyoshi, N.E.; Edwards, D.; Gresshoff, P.M.; Biswas, B.; Batley, J. Scanning the effects of ethyl methanesulfonate on the whole genome of Lotus japonicus using second-generation sequencing analysis. G3 (Bethesda) 2015, 5, 559-567. [CrossRef]

18. Maghuly, F.; Pabinger, S.; Krainer, J.; Laimer, M. The pattern and distribution of induced mutations in J. curcas using reduced representation sequencing. Front. Plant Sci. 2018, 9, 524. [CrossRef] 
19. Li, S.; Zheng, Y.C.; Cui, H.R.; Fu, H.W.; Shu, Q.Y.; Huang, J.Z. Frequency and type of inheritable mutations induced by $\gamma$ rays in rice as revealed by whole genome sequencing. J. Zhejiang Univ. Sci. B 2016, 17, $905-915$. [CrossRef]

20. Zheng, Y.; Li, S.; Huang, J.; Fan, L.; Shu, Q. Identification and characterization of $\gamma$-ray-induced mutations in rice cytoplasmic genomes by whole-genome sequencing. Cytogenet. Genome Res. 2020. [CrossRef]

21. Henry, I.M.; Zinkgraf, M.S.; Groover, A.T.; Comai, L. A system for dosage-based functional genomics in poplar. Plant Cell 2015, 27, 2370-2383. [CrossRef]

22. Belfield, E.J.; Gan, X.; Mithani, A.; Brown, C.; Jiang, C.; Franklin, K.; Alvey, E.; Wibowo, A.; Jung, M.; Bailey, K.; et al. Genome-wide analysis of mutations in mutant lineages selected following fast-neutron irradiation mutagenesis of Arabidopsis thaliana. Genome Res. 2012, 22, 1306-1315. [CrossRef] [PubMed]

23. Li, G.T.; Chern, M.S.; Jain, R.; Martin, J.A.; Schackwitz, W.S.; Jiang, L.; Vega-Sánchez, M.E.; Lipzen, A.M.; Barry, K.W.; Schmutz, J.; et al. Genome-wide sequencing of 41 rice (Oryza sativa L.) mutated lines reveals diverse mutations induced by fast-neutron irradiation. Mol. Plant 2016, 9, 1078-1081. [CrossRef] [PubMed]

24. Du, Y.; Luo, S.; Li, X.; Yang, J.; Cui, T.; Li, W.; Yu, L.; Feng, H.; Chen, Y.; Mu, J.; et al. Identification of substitutions and small insertion-deletions induced by carbon-ion beam irradiation in Arabidopsis thaliana. Front. Plant Sci. 2017, 8, 1851. [CrossRef] [PubMed]

25. Du, Y.; Luo, S.W.; Yu, L.X.; Cui, T.; Chen, X.; Yang, J.Y.; Li, X.; Li, W.J.; Wang, J.F.; Zhou, L.B. Strategies for identification of mutations induced by carbon-ion beam irradiation in Arabidopsis thaliana by whole genome re-sequencing. Mutat. Res. 2018, 807, 21-30. [CrossRef]

26. Hase, Y.; Satoh, K.; Kitamura, S.; Oono, Y. Physiological status of plant tissue affects the frequency and types of mutations induced by carbon-ion irradiation in Arabidopsis. Sci. Rep. 2018, 8, 1394. [CrossRef]

27. Hirano, T.; Kazama, Y.; Ishii, K.; Ohbu, S.; Shirakawa, Y.; Abe, T. Comprehensive identification of mutations induced by heavy-ion beam irradiation in Arabidopsis thaliana. Plant J. 2015, 82, 93-104. [CrossRef]

28. Kazama, Y.; Ishii, K.; Hirano, T.; Wakana, T.; Yamada, M.; Ohbu, S.; Abe, T. Different mutational function of low- and high-linear energy transfer heavy-ion irradiation demonstrated by whole-genome resequencing of Arabidopsis mutants. Plant J. 2017, 92, 1020-1030. [CrossRef]

29. Ichida, H.; Morita, R.; Shirakawa, Y.; Hayashi, Y.; Abe, T. Targeted exome sequencing of unselected heavy-ion beam-irradiated populations reveals less-biased mutation characteristics in the rice genome. Plant J. 2019, 98, 301-314. [CrossRef]

30. Li, F.; Shimizu, A.; Nishio, T.; Tsutsumi, N.; Kato, H. Comparison and characterization of mutations induced by gamma-ray and carbon-ion irradiation in rice (Oryza sativa L.) using whole-genome resequencing. G3 (Bethesda) 2019, 9, 3743-3751. [CrossRef]

31. Yang, G.; Luo, W.; Zhang, J.; Yan, X.; Du, Y.; Zhou, L.; Li, W.; Wang, H.; Chen, Z.; Guo, T. Genome-wide comparisons of mutations induced by carbon-ion beam and gamma-rays irradiation in rice via resequencing multiple mutants. Front. Plant Sci. 2019, 10, 1514. [CrossRef]

32. Feng, H.Y.; Yu, Z.L. Ion implantation mutagenesis. In Plant Mutation Breeding and Biotechnology, 1st ed.; Shu, Q.Y., Forster, B.P., Nakagawa, H., Eds.; Plant Breeding and Genetics Section, Joint FAO/IAEA Division of Nuclear Techniques in Food and Agriculture, International Atomic Energy Agency: Vienna, Austria, 2012; Chapter 10; pp. 107-122.

33. Matsumoto, Y.; Furusawa, Y.; Aoki-Nakano, M.; Matsufuji, N.; Hirayama, R.; Kanai, T.; Ando, K.; Sakurai, H. Estimation of RBE values for carbon-ion beams in the wide dose range using multicellular spheroids. Radiat. Prot. Dosim. 2019, 183, 45-49. [CrossRef] [PubMed]

34. Robinson, J.T.; Thorvaldsdóttir, H.; Winckler, W.; Guttman, M.; Lander, E.S.; Getz, G.; Mesirov, J.P. Integrative genomics viewer. Nat. Biotechnol. 2011, 29, 24-26. [CrossRef] [PubMed]

35. Patel, R.K.; Jain, M. NGS QC Toolkit: A toolkit for quality control of next generation sequencing data. PLoS ONE 2012, 7, e30619. [CrossRef] [PubMed]

36. The Reference Nipponbare Genome. Available online: ftp://ftp.ensemblgenomes.org/pub/plants/release-41/ fasta/oryza_sativa/dna/Oryza_sativa.IRGSP-1.0.dna.toplevel.fa.gz (accessed on 24 April 2020).

37. Li, H.; Durbin, R. Fast and accurate short read alignment with Burrows-Wheeler transform. Bioinformatics 2009, 25, 1754-1760. [CrossRef] [PubMed]

38. Li, H.; Handsaker, B.; Wysoker, A.; Fennell, T.; Ruan, J.; Homer, N.; Marth, G.; Abecasis, G.; Durbin, R. 1000 Genome Project Data Processing Subgroup. The Sequence Alignment/Map format and SAMtools. Bioinformatics 2009, 25, 2078-2079. [CrossRef] [PubMed] 
39. Picard Toolkit, Broad Institute, GitHub Repository. Available online: http://broadinstitute.github.io/picard/ (accessed on 23 March 2020).

40. Calculation of the Coverage and Average Depth. Available online: https://github.com/zhengyunchao/ Inheritable_Mutations_Induced_by_Ion_Beams_in_Rice/blob/master/Calculation_of_the_coverage_and_ average_depth.pl (accessed on 24 April 2020).

41. McKenna, A.; Hanna, M.; Banks, E.; Sivachenko, A.; Cibulskis, K.; Kernytsky, A.; Garimella, K.; Altshuler, D.; Gabriel, S.; Daly, M.; et al. The Genome Analysis Toolkit: A MapReduce framework for analyzing next-generation DNA sequencing data. Genome Res. 2010, 20, 1297-1303. [CrossRef] [PubMed]

42. Koboldt, D.C.; Zhang, Q.; Larson, D.E.; Shen, D.; McLellan, M.D.; Lin, L.; Miller, C.A.; Mardis, E.R.; Ding, L.; Wilson, R.K. VarScan 2: Somatic mutation and copy number alteration discovery in cancer by exome sequencing. Genome Res. 2012, 22, 568-576. [CrossRef]

43. Removal of Common Variants in Any Two Mutants. Available online: https://github.com/zhengyunchao/ Heritable_Mutations_Induced_by_Ion_Beams_in_Rice/blob/master/Removal_of_common_variants_in_ any_two_mutants.pl (accessed on 24 April 2020).

44. Filtration of Variants Called by GATK. Available online: https://github.com/zhengyunchao/Heritable_ Mutations_Induced_by_Ion_Beams_in_Rice/blob/master/Filtration_of_Variants_Called_by_GATK.pl (accessed on 24 April 2020).

45. Filtration of Variants Called by SAMtools. Available online: https://github.com/zhengyunchao/Heritable Mutations_Induced_by_Ion_Beams_in_Rice/blob/master/Filtration_of_Variants_Called_by_SAMtools.pl (accessed on 24 April 2020).

46. Filtration of Variants Called by VarScan2. Available online: https://github.com/zhengyunchao/Heritable_ Mutations_Induced_by_Ion_Beams_in_Rice/blob/master/Filtration_of_Variants_Called_by_VarScan2.pl (accessed on 24 April 2020).

47. Wang, K.; Li, M.; Hakonarson, H. ANNOVAR: Functional annotation of genetic variants from next-generation sequencing data. Nucleic Acids Res. 2010, 38, e164. [CrossRef]

48. Krzywinski, M.; Schein, J.; Birol, I.; Connors, J.; Gascoyne, R.; Horsman, D.; Jones, S.J.; Marra, M.A. Circos: An information aesthetic for comparative genomics. Genome Res. 2009, 19, 1639-1645. [CrossRef]

49. Viewing Alignments in the Integrative Genomics Viewer (IGV). Available online: http://software. broadinstitute.org/software/igv/AlignmentData (accessed on 24 April 2020). 